\title{
Equilibrium Clumped-Isotope Effects in Doubly Substituted Isotopologues of Ethane
}

\author{
Michael A. Webb ${ }^{\mathrm{a}, *}$, Yimin Wang ${ }^{\mathrm{b}}$, Bastiaan J. Braams ${ }^{\mathrm{b}, 1}$, Joel M. Bowman ${ }^{\mathrm{b}}$, Thomas F. Miller III ${ }^{\mathrm{a}, * *}$ \\ ${ }^{a}$ Department of Chemistry and Chemical Engineering, California Institute of Technology, Pasadena, California 91125, USA \\ ${ }^{b}$ Cherry L. Emerson Center for Scientific Computation and Department of Chemistry, Emory University, Atlanta, Georgia \\ 30322, USA
}

\begin{abstract}
We combine path-integral Monte Carlo methods with a new intramolecular potential energy surface to quantify the equilibrium enrichment of doubly substituted ethane isotopologues due to clumped-isotope effects. Ethane represents the simplest molecule to simultaneously exhibit ${ }^{13} \mathrm{C}-{ }^{13} \mathrm{C},{ }^{13} \mathrm{C}-\mathrm{D}$, and D-D clumped-isotope effects, and the analysis of corresponding signatures may provide useful geochemical and biogeochemical proxies of formation temperatures or reaction pathways. Utilizing path-integral statistical mechanics, we predict equilibrium fractionation factors that fully incorporate nuclear quantum effects, such as anharmonicity and rotational-vibrational coupling which are typically neglected by the widely used Urey model. The magnitude of the calculated fractionation factors for the doubly substituted ethane isotopologues indicates that isotopic clumping can be observed if rare-isotope substitutions are separated by up to three chemical bonds, but the diminishing strength of these effects suggests that enrichment at further separations will be negligible. The Urey model systematically underestimates enrichment due to ${ }^{13} \mathrm{C}-\mathrm{D}$ and $\mathrm{D}-\mathrm{D}$ clumpedisotope effects in ethane, leading to small relative errors in the apparent equilibrium temperature, ranging from $5 \mathrm{~K}$ at $273.15 \mathrm{~K}$ to $30 \mathrm{~K}$ at $873.15 \mathrm{~K}$. We additionally note that the rotameric dependence of isotopologue enrichment must be carefully considered when using the Urey model, whereas the path-integral calculations automatically account for such effects due to configurational sampling. These findings are of direct relevance to future clumped-isotope studies of ethane, as well as studies of ${ }^{13} \mathrm{C}-{ }^{13} \mathrm{C},{ }^{13} \mathrm{C}-\mathrm{D}$, and $\mathrm{D}-\mathrm{D}$ clumped-isotope effects in other hydrocarbons.
\end{abstract}

Keywords: Clumped isotope geochemistry, Ethane, Equilibrium isotope effects, Path-integral methods, Vibrational anharmonicity

\footnotetext{
* Corresponding author.

** Principal corresponding author.

Email addresses: mwebb@caltech.edu (Michael A. Webb), yimin.wang@emory.edu (Yimin Wang), B.J.Braams@iaea.org (Bastiaan J. Braams), jmbowma@emory.edu (Joel M. Bowman), tfm@caltech.edu (Thomas F. Miller III)

${ }^{1}$ Present Address: Division of Physical and Chemical Sciences (NAPC), International Atomic Energy Agency, P. O. Box 100, A-1400 Vienna, Austria
} 


\section{Introduction}

The isotopic composition of a material embeds a wealth of information regarding its origin and history (Schoell, 1984; Whiticar, 1990; Sturup et al., 2008, Eiler, 2013, Wolfsberg et al., 2009). Although stable isotope analysis typically focuses on the bulk isotopic composition of materials, which is often dominated by the concentration of molecules containing only one rare isotope, recent advancements in analytical methods enable the explicit and precise measurement of multiply substituted isotopologues (isotopologues with two or more rare-isotope substitutions) at natural abundances (Eiler and Schauble, 2004, Affek and Eiler, 2006. Eiler, 2007, Yeung et al., 2012, Eiler et al., 2013; Stolper et al., 2014a, Ono et al., 2014; Wang et al., 2015. Young et al., 2016; Magyar et al., 2016). The rich diversity of both equilibrium and non-equilibrium fractionation behavior of multiply substituted isotopologues could help to identify or place additional constraints on formation temperatures, sources, or reaction pathways in a variety of molecular systems and organic compounds (see Eiler (2013), Eiler et al. (2014), and references therein).

Recent innovations in isotope-ratio mass spectrometry, infrared absorption spectroscopy, nuclear magnetic resonance techniques, and other instrumentation that can preserve the original bonding connectivity of the analyte enable measurements of isotopically 'clumped' species, in which rare isotopes are spatially co-localized in a molecule (Eiler, 2007, Eiler et al., 2014). At equilibrium, this co-localization of rare isotopes leads to relative enrichment of clumped isotopologues compared to what would be expected from the random distribution of the composite isotopes at natural abundance (Wang et al. 2004). Importantly, this relative enrichment at equilibrium is a function of temperature that depends only on the energetics of homogeneous isotope exchange among isotopologues and not on the absolute abundances of the isotopes themselves, which can vary based on sample origin. Therefore, a useful application of clumped-isotope measurements is to provide a paleothermometer based on the extent of ${ }^{13} \mathrm{C}-{ }^{18} \mathrm{O}$ ordering in carbonate ions (Ghosh et al. 2006 . Eiler, 2011), which has been employed to reconstruct ancient marine ocean environments (Finnegan et al. 2011; Grauel et al. 2013), estimate mountain uplift rate (Ghosh et al., 2006), characterize diagenesis (Huntington et al. 2011), and understand the thermal physiology of extinct vertebrates (Eagle et al., 2010, 2011). More applications of clumped-isotope measurements are emerging, as recent studies have demonstrated capabilities to source methane (Eiler, 2007, Stolper et al., 2014b a, 2015; Wang et al., 2015, Douglas et al. 2016; Young et al., 2016, Wang et al., 2016) and to identify biological signatures in molecular oxygen (Yeung et al. 2015) and nitrous oxide (Magyar et al., 2016).

A natural extension of existing clumped-isotope applications would be to utilize clumped-isotope signatures in hydrocarbon exploration or in stable isotope studies of other organic matter. Carbon and hydrogen isotope ratios have long been used to unravel the complex origins or source processes of samples in geochemistry and biogeochemistry (Craig, 1953, Schoell, 1984, Freeman, KH and Hayes, JM and Trendel, JM and Albrecht, P, 1990, Hayes et al., 1990, Clayton, 1991; Sessions et al., 1999), and clumped-isotope mea- 
surements would add additional constraints and dimensions to this analysis (Ma et al., 2008, Stolper et al., 2014a Eiler, 2013, Wang et al., 2015, Young et al., 2016). Ethane is the simplest molecule that feasibly exhibits ${ }^{13} \mathrm{C}-{ }^{13} \mathrm{C},{ }^{13} \mathrm{C}-\mathrm{D}$, and $\mathrm{D}-{ }^{12} \mathrm{C}-\mathrm{D}$ (henceforth referred to as D-D) clumping effects that could be used to probe fractionation history. Clumping effects in ethane would indicate the balance of thermodynamic and kinetic factors affecting the distribution of isotopes in kerogen, coal, petroleum, and natural gases Clog et al. 2012, Clog and Eiler, 2014, Clog et al., 2014) and may additionally provide insights into the chemistry of more complex organic molecules. Many factors-including gas wetness, diffusion, maturation, and degradation-are likely to affect observed experimental signatures in ethane and other hydrocarbons. However, measurements of clumping in some methane isotopologues have either indicated isotopic equilibrium or partial equilibrium conditions, and deviations can otherwise characterize kinetically controlled formation pathways (Stolper et al., 2014b a, Ono et al., 2014, Stolper et al., 2015, Wang et al., 2015, Douglas et al. 2016; Young et al., 2016, Wang et al. 2016). Therefore, a natural starting point for ethane is quantify the enrichment of isotopologues due to isotopic clumping at equilibrium conditions.

In previous work, we used path-integral methods to compute equilibrium clumped-isotope effects in carbon dioxide and methane (Webb and Miller, 2014), finding that results obtained within the harmonic approximation via the widely used Urey model (Urey, 1947, Bigeleisen and Mayer, 1947) benefited from a large cancellation of errors. However, clumped-isotope effects were not examined in any molecules that exhibit torsional motions. Here, we rigorously and accurately compute equilibrium clumped-isotope effects for the flexible ethane molecule using path-integral Monte Carlo methods and a new full-dimensional, isotopically independent intramolecular potential energy surface that is parameterized from more than 900 energies and gradients at the B3LYP/aug-cc-pVTZ level of theory. We compute fractionation factors for five double-isotope exchange reactions of ethane as functions of temperature. The path-integral calculations are converged to within anticipated experimental precisions of high-resolution mass spectrometry, and comparison among the various equilibrium constants reveals the effect of isotopic clumping on the enrichment of doubly substituted ethane isotopologues. The results of the path-integral calculations are further compared to those obtained via the Urey model, elucidating the errors in this widely used model.

\section{Methodology}

\subsection{Enrichment of Doubly Substituted Isotopologues}

The relative equilibrium enrichment of an isotopologue is quantified as

$$
\Delta_{i}=1000\left[\frac{\left(x_{i} / x_{0}\right)_{\mathrm{eq}}}{\left(x_{i} / x_{0}\right)_{\mathrm{r}}}-1\right],
$$

where $x_{i} / x_{0}$ is the abundance of an isotopologue, $i$, relative to that with no rare-isotope substitutions. The notation $(\cdots)_{\text {eq }}$ indicates an observed quantity at equilibrium conditions, while $(\cdots)_{\mathrm{r}}$ indicates a quantity 
obtained from the stochastic distribution, in which the composite isotopes are distributed randomly among all isotopologues subject to their absolute abundance (Wang et al., 2004, Affek and Eiler, 2006, Eiler, 2007). While $x_{i}$ in Eq. (1) depends on the absolute abundances of its composite isotopes, $\Delta_{i}$ does not, instead indicating the propensity for rare isotopes to clump together. For a doubly substituted isotopologue, $\Delta_{i}$ is primarily controlled by isotope exchange reactions of the form

$$
\mathrm{XY}+\mathrm{X}^{\prime} \mathrm{Y}^{\prime} \stackrel{K}{\rightleftharpoons} \mathrm{XY}^{\prime}+\mathrm{X}^{\prime} \mathrm{Y}
$$

where $\mathrm{X}^{\prime}$ and $\mathrm{Y}^{\prime}$ are rare isotopes of $\mathrm{X}$ and $\mathrm{Y}$, and $K=\frac{\bar{Q}_{\mathrm{XY}}}{\bar{Q}_{\mathrm{XY}}} \frac{\bar{Q}_{\mathrm{X}^{\prime} \mathrm{Y}}}{\bar{Q}_{\mathrm{X}^{\prime} \mathrm{Y}^{\prime}}}$ is the equilibrium constant. The equilibrium constant can thus be computed from the partition functions, denoted as $\bar{Q}_{i j}$ for the various isotopologues in Eq. (2).

An approximate relationship between $\Delta_{\mathrm{X}^{\prime} \mathrm{Y}^{\prime}}$ and $K$ can be derived as

$$
\Delta_{\mathrm{X}^{\prime} \mathrm{Y}^{\prime}}=1000\left[1-\frac{K}{K_{r}}\right]
$$

where $K_{\mathrm{r}}$ is the equilibrium constant in Eq. (2) for isotopologues based on a random distribution of isotopes (Wang et al., 2004, Cao and Liu, 2012, Liu and Liu, 2016, Ono et al., 2014). Eq. (3) has a leading-order error of $\mathcal{O}\left(\Delta_{\mathrm{X}^{\prime} \mathrm{Y}}+\Delta_{\mathrm{XY}^{\prime}}\right)$, which is generally small when there are no structural isotopomers for singly substituted species (Wang et al. 2004, Cao and Liu, 2012) (as is the case for the specific reactions considered in this study) and will partially cancel with higher-order error terms (Liu and Liu, 2016).

Here, we will assume that $\bar{Q}_{i j}=\sigma_{i j}^{-1} Q_{i j}$, where $\sigma_{i j}$ is a classical, rotational symmetry number and $Q_{i j}$ is a reduced partition function. To describe isotopologue enrichment associated with Eq. (3) without the need to explicitly specify symmetry numbers or reference isotopologues, we shall simply report the fractionation factor $\alpha=\frac{Q_{\mathrm{XY}^{\prime}}}{Q_{\mathrm{XY}}} \frac{Q_{\mathrm{X}^{\prime} \mathrm{Y}}}{Q_{\mathrm{X}^{\prime} \mathrm{Y}^{\prime}}}$, which is related to the equilibrium constant via $\alpha=K \frac{\sigma_{\mathrm{XY}^{\prime}} \sigma_{\mathrm{X}^{\prime} \mathrm{Y}}}{\sigma_{\mathrm{XY}^{\prime}} \sigma_{\mathrm{X}^{\prime} \mathrm{Y}^{\prime}}}$.

\subsection{Path Integral Calculations}

The Feynman path-integral (PI) formulation of quantum statistical mechanics (Feynman and Hibbs, 1965 provides a rigorous framework that has been widely employed to include nuclear quantum effects in the computation of equilibrium isotope effects in many gas-phase and condensed-phase systems Balog et al. 2000, Bohm et al., 2001, Chen et al., 2003, Lynch et al., 2004, de la Peña and Kusalik, 2004, Lynch et al., 2005, Paesani et al., 2007; Mielke and Truhlar, 2009, Zimmermann and Vaníček, 2009; Habershon and Manolopoulos, 2011; Azuri et al., 2011; Pérez and von Lilienfeld, 2011, Herrero and Ramirez, 2011, Mielke and Truhlar, 2012, Buchowiecki, 2012; Markland and Berne, 2012, Liu et al., 2013, Ceriotti and Markland, 2013: Mielke et al. 2013; Buchowiecki and Vaníček, 2013; Webb and Miller, 2014, Cheng and Ceriotti, 2014, Pinilla et al., 2014, Buchowiecki, 2015, 2016). Under the PI formalism, the quantum mechanical canonical partition function for a system of $N$ distinguishable particles obeying Boltzmann statistics can be expressed 
as a classical configuration integral (Chandler and Wolynes, 1981),

$$
\begin{aligned}
Q(N, \beta)= & \lim _{P \rightarrow \infty} \prod_{i=1}^{N}\left(\frac{m_{i} P}{2 \pi \beta \hbar^{2}}\right)^{3 P / 2} \\
& \times \int \prod_{j=1}^{N} \prod_{k=1}^{P} d \boldsymbol{r}_{j}^{(k)} e^{-\beta_{P} U_{P}\left(\left\{\boldsymbol{r}_{j}^{(k)}\right\}\right)}
\end{aligned}
$$

Through Eq. (4), the quantum Boltzmann statistics of the system are obtained from the classical statistics of a ring-polymer with $P$ beads at inverse temperature $\beta_{P}=\beta / P$ that interact via an effective potential,

$$
\begin{aligned}
U_{P}\left(\left\{\boldsymbol{r}_{j}^{(k)}\right\}\right) & =\sum_{j=1}^{N} \sum_{k=1}^{P}\left(\frac{1}{2} m_{j} \omega_{P}^{2}\left(\boldsymbol{r}_{j}^{(k)}-\boldsymbol{r}_{j}^{(k-1)}\right)^{2}\right) \\
& +\sum_{k=1}^{P} U\left(\boldsymbol{r}_{1}^{(k)}, \ldots, \boldsymbol{r}_{N}^{(k)}\right) .
\end{aligned}
$$

Here, $\boldsymbol{r}_{j}^{(k)}$ indicates the position of the $j$ th atom in the $k$ th ring-polymer bead, $\omega_{P}=1 /\left(\beta_{P} \hbar\right)$ is the intra-bead vibrational frequency, $\boldsymbol{r}^{(0)}=\boldsymbol{r}^{(P)}$, and $U\left(\boldsymbol{r}_{1}, \ldots, \boldsymbol{r}_{N}\right)$ is the Born-Oppenheimer potential energy surface for the molecular system, or the molecular potential. For a given PES, PI-based approaches thus yield a fully anharmonic description of the partition function, obtainable through Boltzmann-weighted configurational sampling using classical simulation techniques; this approach contrasts with the more widely used Urey model (Section 2.3 that employs electronic structure methods to obtain harmonic approximations to the partition function, perhaps in combination with approximate anharmonic corrections (Richet et al., 1977 , Barone, 2004, Liu et al., 2010, Cao and Liu, 2012, Liu and Liu, 2016) or limited conformational sampling (Rustad et al., 2008, 2010; Hill et al., 2014).

There are a variety of path-integral free-energy methods and estimators available for computing isotopic fractionation (Mielke and Truhlar, 2009, Zimmermann and Vaníček, 2009, Azuri et al., 2011, Ceriotti and Markland, 2013, Buchowiecki and Vaníček, 2013; Webb and Miller, 2014, Marsalek et al., 2014, Cheng and Ceriotti, 2014). Here, we compute the fractionation factors for reactions in the form of Eq. (2) as

$$
\alpha=\frac{\left\langle\mathcal{Z}_{\mathrm{X}^{\prime}, \mathrm{X}}\right\rangle_{\mathrm{X}^{\prime} \mathrm{Y}}}{\left\langle\mathcal{Z}_{\mathrm{X}^{\prime}, \mathrm{X}}\right\rangle_{\mathrm{X}^{\prime} \mathrm{Y}^{\prime}}}
$$

11 where $\langle\cdots\rangle_{\mathrm{X}^{\prime} \mathrm{Y}}$ and $\langle\cdots\rangle_{\mathrm{X}^{\prime} \mathrm{Y}^{\prime}}$ denote ensemble averages obtained from simulation of $\mathrm{X}^{\prime} \mathrm{Y}$ and $\mathrm{X}^{\prime} \mathrm{Y}^{\prime}$, respectively, and $\mathcal{Z}_{A^{\prime}, A}$ is a direct scaled-coordinates estimator involving the exchange of an isotope $A^{\prime}$ for that of 


$$
\begin{array}{r}
\mathcal{Z}_{A^{\prime}, A} \equiv \exp \left[-\beta_{P} \sum_{k=1}^{P}\left(U\left(\boldsymbol{q}_{1}^{(k)}, \ldots, \boldsymbol{q}_{N}^{(k)}\right)\right.\right. \\
\left.\left.-U\left(\boldsymbol{r}_{1}^{(k)}, \ldots, \boldsymbol{r}_{N}^{(k)}\right)\right)\right],
\end{array}
$$

is an estimator involving the difference in molecular potential between the given ring-polymer configuration and that with scaled-coordinates $\boldsymbol{q}_{j}^{(k)}=\overline{\boldsymbol{r}}_{j}+\sqrt{\frac{m_{A}}{m_{A^{\prime}}}}\left(\boldsymbol{r}_{j}^{(k)}-\overline{\boldsymbol{r}}_{j}\right)$ where $\overline{\boldsymbol{r}}_{j}=\sum_{k=1}^{P} \boldsymbol{r}_{j}^{(k)}$ is the position of the ring-polymer centroid for the $j$ th atom, and $m_{A^{\prime}}$ and $m_{A}$ are masses of the isotopes $A^{\prime}$ and $A$. We note that Eqs. (6) and (7) are written such that simulations are performed on isotopologues with more rareisotope substitutions, which should generally lead to smaller statistical errors than performing the opposite substitution (Cheng and Ceriotti, 2014).

\subsection{Urey Model}

To compare with the PI calculations, we also compute equilibrium constants for isotope exchange reactions using the Urey model or Bigeleisen-Mayer equation (Urey, 1947; Bigeleisen and Mayer, 1947). Using the rigid-rotor, harmonic-oscillator approximation and the Teller-Redlich product rule (Redlich, 1935, McQuarrie, 2000), the Urey model provides a convenient way to compute the reduced (ignoring symmetry numbers) partition function ratio between two isotopologues as

$$
\begin{aligned}
\frac{Q^{\prime}}{Q} & =e^{-\beta\left[E^{\prime(0)}-E^{(0)}\right]} \prod_{i=1}^{N}\left(\frac{m_{i}^{\prime}}{m_{i}}\right)^{3 / 2} \\
& \times \prod_{j=1}^{\alpha} \frac{\omega^{\prime(j)}}{\omega^{(j)}}\left(\frac{1-\exp \left[-\beta \hbar \omega^{(j)}\right]}{1-\exp \left[-\beta \hbar \omega^{(j)}\right]}\right),
\end{aligned}
$$

where $\beta=1 /\left(k_{\mathrm{B}} T\right)$ is the inverse temperature, $E^{(0)}$ is the zero-point energy, $m_{i}$ is the mass of the $i$ th atom in a molecule of $N$ atoms, $\omega^{(j)}$ is the harmonic frequency of the $j$ th normal mode, and $\alpha$ is the total number of normal vibrational modes ( $\alpha=3 N-5$ for linear molecules and $3 N-6$ for nonlinear molecules). The mass terms precisely cancel in calculating fractionation factors, such that

$$
\begin{aligned}
\alpha & =e^{-\beta \Delta E^{(0)}} \prod_{j=1}^{\alpha} \frac{\omega_{\mathrm{X}^{\prime} \mathrm{Y}}^{(j)} \omega_{\mathrm{XY}}^{(j)} \omega_{\mathrm{X}^{\prime} \mathrm{Y}^{\prime}}^{(j)} \omega_{\mathrm{XY}}^{(j)}}{} \\
& \times\left(\frac{1-\exp \left[-\beta \hbar \omega_{\mathrm{XY}}^{(j)}\right]}{1-\exp \left[-\beta \hbar \omega_{\mathrm{X}^{\prime} \mathrm{Y}}^{(j)}\right]}\right)\left(\frac{1-\exp \left[-\beta \hbar \omega_{\mathrm{X}^{\prime} \mathrm{Y}^{\prime}}^{(j)}\right]}{1-\exp \left[-\beta \hbar \omega_{\mathrm{XY}^{\prime}}^{(j)}\right]}\right),
\end{aligned}
$$

where $\Delta E^{(0)}$ is the zero-point energy change for Eq. (2). If the zero-point energy is calculated purely from harmonic vibrational contributions, i.e., $E_{0}=\frac{1}{2} \sum_{j=1}^{\alpha} \hbar \omega_{j}$ for each isotopologue, then Eq. (9) depends only 
on variation of the harmonic frequencies among the isotopologues.

It is possible to include higher-order, perturbative corrections to Eq. (9), such as those due to vibrational anharmonicity, rovibrational coupling, quantum mechanical rotations, and centrifugal distortion (Richet et al. 1977; Barone, 2004, Liu et al., 2010, Cao and Liu, 2012; Liu and Liu, 2016). Such corrections may improve calculations of partition function ratios and equilibrium constants (Liu et al., 2010; Liu and Liu, 2016). However, including only partial corrections to Eq. (9) can be detrimental to the overall accuracy of Eq. (3) due to a nontrivial cancellation of errors (Webb and Miller, 2014), and the corrections generally require computation of a large number of molecular constants such that they are not easily or widely employed (Liu et al., 2010, Liu and Liu, 2016). Therefore, we only compare the PI results with those based on the pure rigid-rotor, harmonic oscillator approximation.

\section{Calculation Details}

\subsection{Double Isotope Exchange Reactions in Ethane}

Isotopologues featuring two rare-isotope substitutions will have the most practical relevance for near-term clumped-isotope studies of ethane (Clog et al., 2012, Clog and Eiler, 2014, Clog et al., 2014). To quantify the equilibrium enrichment of doubly substituted isotopologues and the strength of isotopic clumping, we focus on five isotope-exchange reactions featuring distinct, doubly substituted ethane isotopologues.

$$
\begin{array}{r}
{ }^{12} \mathrm{CH}_{3}{ }^{12} \mathrm{CH}_{3}+{ }^{13} \mathrm{CH}_{3}{ }^{13} \mathrm{CH}_{3} \stackrel{\alpha_{1}}{\rightleftharpoons} \\
2 \cdot{ }^{12} \mathrm{CH}_{3}{ }^{13} \mathrm{CH}_{3} .
\end{array}
$$

The fractionation factor for this reaction is $\alpha_{1}=R_{12 \rightarrow 13} \mathrm{CH}_{3}{ }^{12} \mathrm{CH}_{3} / R_{12 \rightarrow 13} \mathrm{CH}_{3}{ }^{13} \mathrm{CH}_{3}$, where $R_{12} \mathrm{CH}_{3}{ }^{12 \rightarrow 13} \mathrm{CH}_{3}=$ $Q^{12} \mathrm{CH}_{3}{ }^{13} \mathrm{CH}_{3} / Q^{12} \mathrm{CH}_{3}{ }^{12} \mathrm{CH}_{3}$ and $R_{12 \rightarrow 13} \mathrm{CH}_{3}{ }^{13} \mathrm{CH}_{3}=Q^{13} \mathrm{CH}_{3}{ }^{13} \mathrm{CH}_{3} / Q^{12} \mathrm{CH}_{3}{ }^{13} \mathrm{CH}_{3}$. Eq. 10 is expected to dominate the equilibrium signature of the ${ }^{13} \mathrm{C}-{ }^{13} \mathrm{C}$ clumped-isotope effect.

The second reaction is given by

$$
\begin{array}{r}
{ }^{12} \mathrm{CH}_{3}{ }^{12} \mathrm{CH}_{3}+{ }^{12} \mathrm{CH}_{3}{ }^{13} \mathrm{CH}_{2} \mathrm{D} \stackrel{\alpha_{2}}{\rightleftharpoons} \\
{ }^{12} \mathrm{CH}_{3}{ }^{12} \mathrm{CH}_{2} \mathrm{D}+{ }^{12} \mathrm{CH}_{3}{ }^{13} \mathrm{CH}_{3} .
\end{array}
$$

The fractionation factor for this reaction is $\alpha_{2}=R_{12} \mathrm{CH}_{3}{ }^{12 \rightarrow 13} \mathrm{CH}_{3} / R_{12} \mathrm{CH}_{3}{ }^{12 \rightarrow 13} \mathrm{CH}_{2} \mathrm{D}$, where $R_{12} \mathrm{CH}_{3}{ }^{12 \rightarrow 13} \mathrm{CH}_{2} \mathrm{D}=$ $Q^{12} \mathrm{CH}_{3}{ }^{13} \mathrm{CH}_{2} \mathrm{D} / Q^{12} \mathrm{CH}_{3}{ }^{12} \mathrm{CH}_{2} \mathrm{D}$. Eq 11 is expected to dominate the equilibrium signature for the ${ }^{13} \mathrm{C}-\mathrm{D}$ clumped-isotope effect. 
The third reaction is given by

$$
\begin{gathered}
{ }^{12} \mathrm{CH}_{3}{ }^{12} \mathrm{CH}_{3}+{ }^{13} \mathrm{CH}_{3}{ }^{12} \mathrm{CH}_{2} \mathrm{D} \stackrel{\alpha_{3}}{\rightleftharpoons} \\
{ }^{12} \mathrm{CH}_{3}{ }^{12} \mathrm{CH}_{2} \mathrm{D}+{ }^{12} \mathrm{CH}_{3}{ }^{13} \mathrm{CH}_{3} .
\end{gathered}
$$

The fractionation factor for this reaction is $\alpha_{3}=R^{12} \mathrm{CH}_{3}{ }^{12 \rightarrow 13} \mathrm{CH}_{3} / R^{12 \rightarrow 13} \mathrm{CH}_{3}{ }^{12} \mathrm{CH}_{2} \mathrm{D}$, where $R^{12 \rightarrow 13} \mathrm{CH}_{3}{ }^{12} \mathrm{CH}_{2} \mathrm{D}=$ $Q^{13} \mathrm{CH}_{3}{ }^{12} \mathrm{CH}_{2} \mathrm{D} / Q_{12} \mathrm{CH}_{3}{ }^{12} \mathrm{CH}_{2} \mathrm{D}$. Eq $(12)$ features the same singly substituted isotopologues as Eq. (11), but the two isotope substitutions are separated by an additional bond. Thus, a comparison of the equilibrium constants for Eqs. (11) and (12) implicitly assesses the strength of the ${ }^{13} \mathrm{C}-\mathrm{D}$ clumped-isotope effect. Additionally, $\alpha_{2} / \alpha_{3}$ provides the thermodynamic driving force for hydrogen migration due to ${ }^{13} \mathrm{C}-\mathrm{D}$ clumping.

The fourth reaction is given by

$$
\begin{array}{r}
{ }^{12} \mathrm{CH}_{3}{ }^{12} \mathrm{CH}_{3}+{ }^{12} \mathrm{CH}_{3}{ }^{12} \mathrm{CHD}_{2} \stackrel{\alpha_{4}}{\rightleftharpoons} \\
2 \cdot{ }^{12} \mathrm{CH}_{3}{ }^{12} \mathrm{CH}_{2} \mathrm{D} .
\end{array}
$$

$$
\begin{aligned}
& \text { The fractionation factor for this reaction is } \alpha_{4}=R_{12} \mathrm{CH}_{3}{ }^{12} \mathrm{CH}_{2}(\mathrm{H} \rightarrow \mathrm{D}) / R^{12} \mathrm{CH}_{3}{ }^{12} \mathrm{CHD}(\mathrm{H} \rightarrow \mathrm{D}) \text {, where } R^{12} \mathrm{CH}_{3}{ }^{12} \mathrm{CH}_{2}(\mathrm{H} \rightarrow \mathrm{D})= \\
& \left.Q^{12} \mathrm{CH}_{3}{ }^{12} \mathrm{CH}_{2} \mathrm{D} / Q^{12} \mathrm{CH}_{3}{ }^{12} \mathrm{CH}_{3} \text { and } R^{12} \mathrm{CH}_{3}{ }^{12} \mathrm{CHD}(\mathrm{H} \rightarrow \mathrm{D})=Q^{12} \mathrm{CH}_{3}{ }^{12} \mathrm{CHD}_{2} / Q^{12} \mathrm{CH}_{3}{ }^{12} \mathrm{CH}_{2} \mathrm{D} \text { Eq. } 13\right) \text { is expected } \\
& \text { to dominate the equilibrium signature of the D-D clumped-isotope effect. } \\
& \text { The fifth reaction is given by } \\
& \qquad{ }^{12} \mathrm{CH}_{3}{ }^{12} \mathrm{CH}_{3}+{ }^{12} \mathrm{CH}_{2} \mathrm{D}^{12} \mathrm{CH}_{2} \mathrm{D} \stackrel{\alpha_{5}}{\rightleftharpoons} \\
& \qquad 2 \cdot{ }^{12} \mathrm{CH}_{3}{ }^{12} \mathrm{CH}_{2} \mathrm{D} \text {. }
\end{aligned}
$$$$
Q^{12} \mathrm{CH}_{3}{ }^{12} \mathrm{CH}_{2} \mathrm{D} / Q^{12} \mathrm{CH}_{3}{ }^{12} \mathrm{CH}_{3} \text { and } R_{12} \mathrm{CH}_{3}{ }^{12} \mathrm{CHD}(\mathrm{H} \rightarrow \mathrm{D})=Q^{12} \mathrm{CH}_{3}{ }^{12} \mathrm{CHD}_{2} / Q^{12} \mathrm{CH}_{3}{ }^{12} \mathrm{CH}_{2} \mathrm{D} \text { Eq. } 13 \text { is expected }
$$

The fractionation factor for this reaction is $\alpha_{5}=R_{12} \mathrm{CH}_{3}{ }^{12} \mathrm{CH}_{2}(\mathrm{H} \rightarrow \mathrm{D}) / R_{12} \mathrm{CH}_{2} \mathrm{D}^{12} \mathrm{CHD}(\mathrm{H} \rightarrow \mathrm{D})$, where $R_{12} \mathrm{CH}_{2} \mathrm{D}^{12} \mathrm{CHD}(\mathrm{H} \rightarrow \mathrm{D})=Q^{12} \mathrm{CH}_{2} \mathrm{D}^{12} \mathrm{CH}_{2} \mathrm{D} / Q^{12} \mathrm{CH}_{3}{ }^{12} \mathrm{CH}_{2} \mathrm{D}$. Because this reaction features the same singly substituted isotopologues as Eq. [13], a comparison of $\alpha_{4}$ and $\alpha_{5}$ implicitly assesses the strength of the D-D clumped-isotope effect, and $\alpha_{4} / \alpha_{5}$ provides the thermodynamic driving force for hydrogen migration due to D-D clumping.

In Eq. (14), the isotopologue ${ }^{12} \mathrm{CH}_{2} \mathrm{D}^{12} \mathrm{CH}_{2} \mathrm{D}$ has distinct trans and gauche rotamers (with respect to the positioning of the deuterium atoms) at its minimum energy configuration that exhibit different normalmode vibrational frequencies and will thus yield different results for the Urey model (Eq. (8)) (Wang et al., 2009: Webb and Miller, 2014). In this case, the results of the two rotamers are presented separately, and a third result is obtained by Boltzmann-averaging over the partition functions for each rotamer. Hereafter, we will refer to the trans rotamer as $t-\left({ }^{12} \mathrm{CH}_{2} \mathrm{D}\right)_{2}$ and the gauche rotamer as $g-\left({ }^{12} \mathrm{CH}_{2} \mathrm{D}\right)_{2}$.

As previously noted, the fractionation factor $\alpha$ can be directly computed without specification of rotational symmetry numbers or reference isotopologues. Nonetheless, the results for $\alpha$ can be directly converted 
to those for an equilibrium constant after specification of the isotopologue symmetry numbers $(\sigma=6,6,3,1$, 1,1, 1, 2, and 2 for ${ }^{12} \mathrm{CH}_{3}{ }^{12} \mathrm{CH}_{3},{ }^{13} \mathrm{CH}_{3}{ }^{13} \mathrm{CH}_{3},{ }^{12} \mathrm{CH}_{3}{ }^{13} \mathrm{CH}_{3},{ }^{12} \mathrm{CH}_{3}{ }^{13} \mathrm{CH}_{2} \mathrm{D},{ }^{12} \mathrm{CH}_{3}{ }^{12} \mathrm{CH}_{2} \mathrm{D},{ }^{13} \mathrm{CH}_{3}{ }^{12} \mathrm{CH}_{2} \mathrm{D}$, ${ }^{12} \mathrm{CH}_{3}{ }^{12} \mathrm{CHD}_{2}, t-\left({ }^{12} \mathrm{CH}_{2} \mathrm{D}\right)_{2}$, and $\left.g-\left({ }^{12} \mathrm{CH}_{2} \mathrm{D}\right)_{2}\right)$. For Eqs. 10$)-(13)$, the values of the stochastic equilibrium constant $K_{r}$ for Eqs. (10)-13 are 4, 2, 2, and 6, respectively. For these cases, $\alpha=K / K_{r}$ such that Eqs. (3) and $1000(1-\alpha)$ yield identical results for the enrichment of doubly substituted isotopologues. For Eq. (14), the stochastic equilibrium constant depends on which rotamers of ${ }^{12} \mathrm{CH}_{2} \mathrm{D}^{12} \mathrm{CH}_{2} \mathrm{D}$ are employed as the reference (i.e., $K_{r}=12$ if only $t-\left({ }^{12} \mathrm{CH}_{2} \mathrm{D}\right)_{2}$ is used, 6 if only $g-\left({ }^{12} \mathrm{CH}_{2} \mathrm{D}\right)_{2}$ is used, or 4 if both are used). In this case, $\alpha$ and $K / K_{r}$ are related by a reference-dependent constant, and one can convert between $\alpha$ and Eq. (3) after the desired reference for ${ }^{12} \mathrm{CH}_{2} \mathrm{D}^{12} \mathrm{CH}_{2} \mathrm{D}$ is chosen.

\subsection{Potential Energy Surface}

The ethane molecular potential energy surface (PES) is a full-dimensional, linear-least-squares fit to roughly 900 electronic energies and gradients, obtained at the DFT-B3LYP/aug-cc-pVTZ level of theory. The data set is extensive in configuration space. The fit is given as a sum of two-body potentials plus one eight-body potential. All of these are expressed in terms of products of polynomials of primary invariant polynomials and secondary invariant polynomials in 28 Morse variables, $y_{i j}=\exp \left(-r_{i j} / 2 a_{0}\right)$, where $r_{i j}$ are all internuclear distances and $a_{0}$ is the Bohr radius. Details of this fitting approach have been given in a review article (Braams and Bowman, 2009). For the present fit, there are nine two-body terms (C-H, C-C, H-H) up to the second order and 855 terms with a maximum degree of five for the eight-body potential. Thus a total of 864 linear coefficients were determined by standard least-squares fitting. While the analytical fit does not distinguish among the various contributions to the energy for a given configuration, it does include the effects of intramolecular motions that might otherwise be modeled as bond stretches, angle bends, and torsional motions as well as their anharmonic contributions at the specified level of theory. The root mean square fitting error is not uniform for the energies used in the fit. For energies of relevance to the calculations reported here, i.e., within $30 \mathrm{kcal} / \mathrm{mol}$ of the global energy minimum, the fitting error is of the order of 0.1 $\mathrm{kcal} / \mathrm{mol}$.

This level of electronic structure theory is not expected to provide spectroscopic accuracy. With that in mind, the standard measures of the quality of the PES have been determined. Specifically, the energy of the torsional saddle point is $2.1 \mathrm{kcal} / \mathrm{mol}$, which is in reasonable agreement with the CCSD $(\mathrm{T}) / \mathrm{CBS}$ value of $2.7 \mathrm{kcal} / \mathrm{mol}$ (Halpern and Glendening, 2003). The geometry of the minimum agrees well with previous calculations, albeit done at the MP2/6-311G** level of theory (Hidalgo-Olguín et al., 2008). Finally, normalmode harmonic frequencies from the current PES are also in good agreement with previous MP2/SBK(d) and MP2/pVTZ results (Benoit, 2004), and the frequency shifts between isotopologues are in broad agreement with recent calculations at the B3LYP/6-311G** level of theory (Piasecki et al. 2016). Harmonic frequencies for all the isotopologues featured in this study are provided in Table1. The PES is available upon request. 


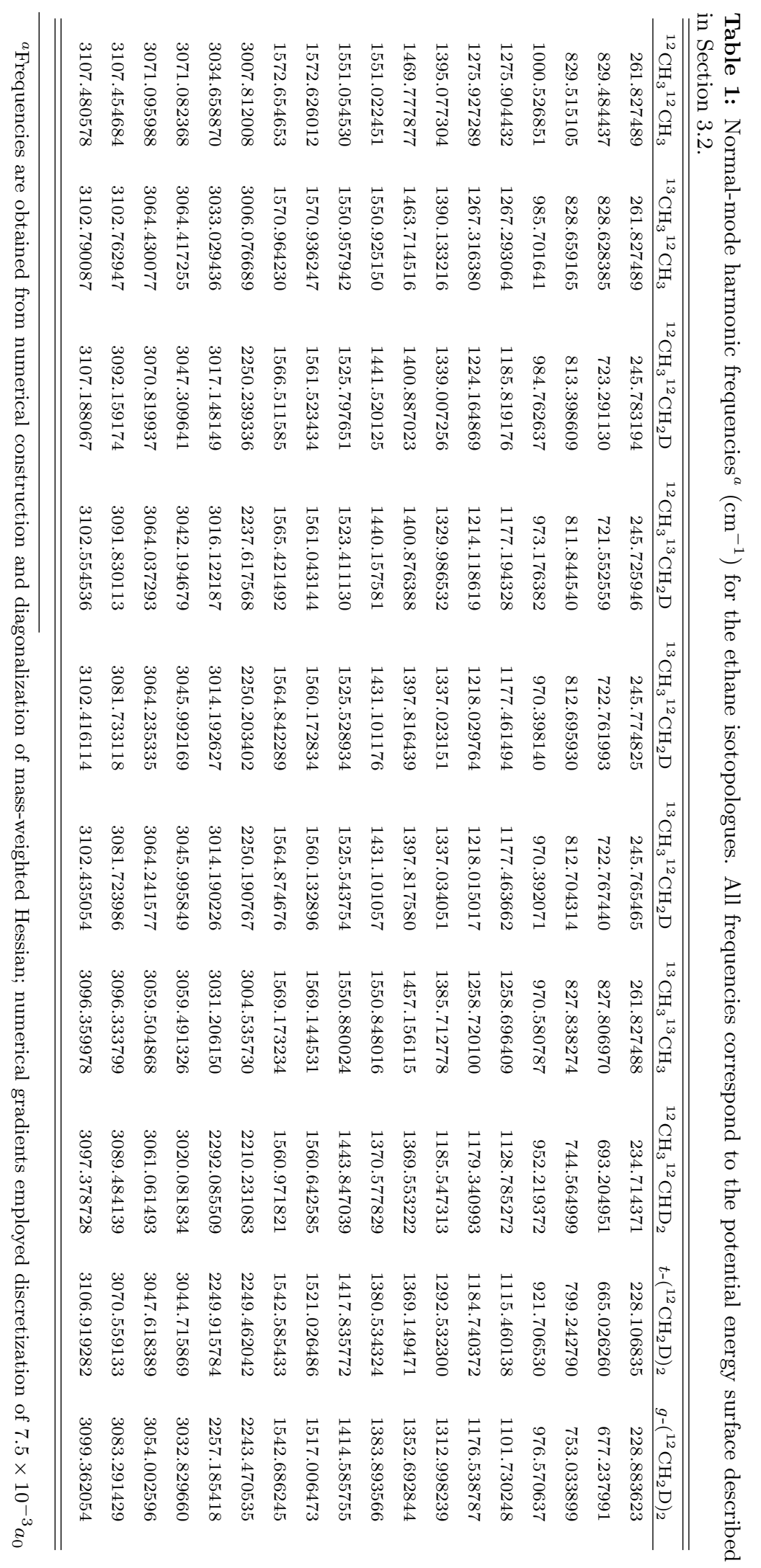




\subsection{PI Calculations}

The fractionation factors for Eqs. (10)-(14) are computed from $T=273.15 \mathrm{~K}$ to $873.15 \mathrm{~K}$ in increments of $100 \mathrm{~K}$. Each fractionation factor is computed using Eqs. (6) and (7), where the average scaled-coordinates estimator is obtained from sampling configurations of the heavy isotopologue for each partition function ratio defined in Section 3.1 using path-integral Monte Carlo (PIMC).

All PIMC sampling trajectories are performed in Cartesian coordinates with an explicit staging transformation (Tuckerman, 2010). The staging length, $j$, is set such that $38-42 \%$ of all staging moves are accepted for trajectories of ${ }^{12} \mathrm{CH}_{2} \mathrm{D}^{12} \mathrm{CH}_{2} \mathrm{D}$; that same $j$ is used in simulations of all other isotopologues at a given temperature. Prior to any data collection, each sampling trajectory is equilibrated for $10^{6} \mathrm{MC}$ steps, with $P / j$ staging moves (rounded up to the nearest integer) attempted per step. Thereafter, Eq. (7) is evaluated from ring-polymer configurations every $10 \mathrm{MC}$ steps. In some cases, isotopologues have multiple equivalent sites for isotope exchange, i.e., ${ }^{12} \mathrm{CH}_{2} \mathrm{D}^{12} \mathrm{CH}_{2} \mathrm{D}$ going to ${ }^{12} \mathrm{CH}_{3}{ }^{12} \mathrm{CH}_{2} \mathrm{D}$, in which case Eq. (7) is evaluated for both equivalent exchanges at the same ring-polymer configuration. An aggregate total of $2.1 \times 10^{8} \mathrm{MC}$ steps is run to compute all partition function ratios at each temperature, except for partition function ratios associated with Eq. (14). As a convergence check for Eq. (14), two separate sets of sampling trajectories are run for ${ }^{12} \mathrm{CH}_{2} \mathrm{D}^{12} \mathrm{CH}_{2} \mathrm{D}$, one set with configurations initialized in approximately trans configurations and another with configurations initialized in approximately gauche configurations. Estimators for both sets are obtained independently with each set being run for an aggregate total of $4.2 \times 10^{8} \mathrm{MC}$ steps, and the estimators from the two sets are found to be within statistical error with the number of MC steps run. Statistical uncertainties for the PIMC calculations are reported as the standard error of the mean obtained from bootstrap error estimation after partitioning the data into sample points where each sample point is an average of $10^{4}$ estimator values.

To ensure that the PI calculations are sufficiently converged with respect to the number of ring-polymer beads, the equilibrium constant for Eq. 13 is computed at $T=273.15 \mathrm{~K}$ for $P=8,16,32,64,96$ and 128 . We choose Eq. (13) because it involves two hydrogen/deuterium exchanges, and tests using the analytical expression for the primitive PI discretization of the partition function for a simple harmonic oscillator (Schweizer et al., 1981) suggest that it is the most stringent test for convergence based on differences in harmonic frequencies between reactant and product isotopologues (Webb and Miller, 2014). Figure 1 illustrates the convergence of $1000\left(1-\alpha_{4}\right)$ as a function of $P$. The figure shows that the results are statistically indistinguishable when using 32 beads compared to using 128 beads. In addition, the calculations are converged within anticipated experimental precisions for D-D clumping of about 1\%, and the calculations are likely even more accurate for the heavier isotope substitutions. Based on these tests, we employ $P=64$ for all calculations discussed in the remainder of the text. 


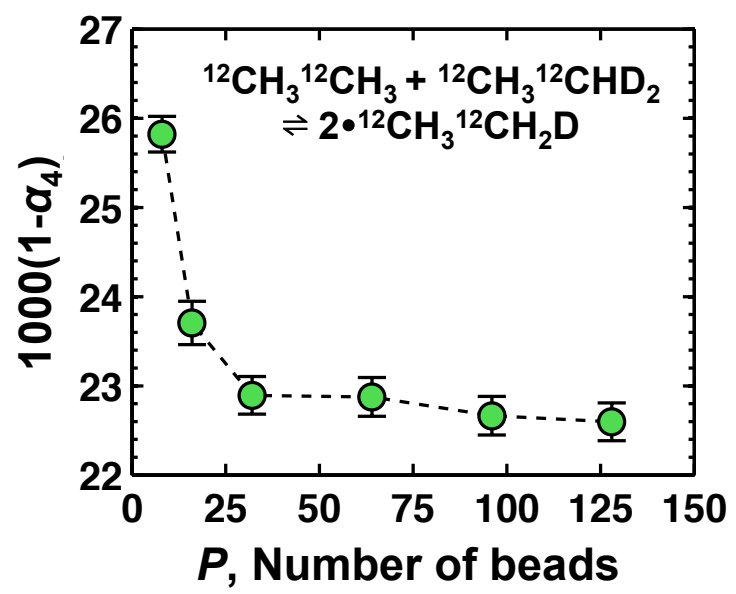

Figure 1: Convergence of the fractionation factor for the isotope exchange reaction given by Eq. (13) at $T=273.15$ $\mathrm{K}$ as a function of the number of ring-polymer beads, $P$. Error bars indicate the standard error of the mean obtained from bootstrap error estimation.

\section{Results}

\subsection{PI Calculation of Isotopologue Enrichment}

We begin by considering the relative enrichment of the doubly substituted isotopologues of ethane${ }^{13} \mathrm{CH}_{3}{ }^{13} \mathrm{CH}_{3},{ }^{12} \mathrm{CH}_{3}{ }^{13} \mathrm{CH}_{2} \mathrm{D},{ }^{13} \mathrm{CH}_{3}{ }^{12} \mathrm{CH}_{2} \mathrm{D},{ }^{12} \mathrm{CH}_{3}{ }^{12} \mathrm{CHD}_{2}$, and ${ }^{12} \mathrm{CH}_{2} \mathrm{D}^{12} \mathrm{CH}_{2} \mathrm{D}$-as functions of temperature as obtained from PIMC.

Figure 2 shows the extent that clumped-isotope effects influence relative isotopologue enrichment in ethane. Figure 2 plots the enrichment of the doubly substituted isotopologues as quantified by $1000\left(1-\alpha_{i}\right)$ for the respective double isotope-exchange reactions in Section 3.1 at various temperatures as predicted by PIMC (markers); the corresponding numerical results are provided in Table 2, Among the isotopologues shown, the largest enrichment is for the doubly-deuterated ${ }^{12} \mathrm{CH}_{3}{ }^{12} \mathrm{CHD}_{2}$ (green circles) due to the $\mathrm{D}-\mathrm{D}$ clumping effect, while the the next largest is due to the ${ }^{13} \mathrm{C}-\mathrm{D}$ clumping effect for ${ }^{12} \mathrm{CH}_{3}{ }^{13} \mathrm{CH}_{2} \mathrm{D}(\mathrm{blue}$ squares). By comparison, the effect of direct ${ }^{13} \mathrm{C}-{ }^{13} \mathrm{C}$ is quite small. For example at $T=273.15 \mathrm{~K}$, the enrichment for ${ }^{12} \mathrm{CH}_{3}{ }^{12} \mathrm{CHD}_{2}$ is about 3.5 times larger than that of ${ }^{12} \mathrm{CH}_{3}{ }^{13} \mathrm{CH}_{2} \mathrm{D}$, which is in turn larger than that of ${ }^{13} \mathrm{CH}_{3}{ }^{13} \mathrm{CH}_{3}$ (gray triangles) by a factor of nearly 23. The remaining enrichments for ${ }^{13} \mathrm{CH}_{3}{ }^{12} \mathrm{CH}_{2} \mathrm{D}$ and ${ }^{12} \mathrm{CH}_{2} \mathrm{D}^{12} \mathrm{CH}_{2} \mathrm{D}$, which do not feature direct isotopic clumping, are all less than one over the entire temperature range. This is clearly seen in Figure $2 \mathrm{~B}$, which shows an expanded view of the same data in Figure 2/A. These results indicate that isotope substitution at separate methyl groups leads to thermodynamic enrichment, but the effect is significantly diminished compared to isotope substitution at the same methyl group. Considering isotopologues with substitutions at separate methyl groups, enrichments for ${ }^{13} \mathrm{CH}_{3}{ }^{13} \mathrm{CH}_{3},{ }^{13} \mathrm{CH}_{3}{ }^{12} \mathrm{CH}_{2} \mathrm{D}$ (red diamonds), and ${ }^{12} \mathrm{CH}_{2} \mathrm{D}^{12} \mathrm{CH}_{2} \mathrm{D}$ (left-facing triangles) are all similar over the entire temperature range despite the variation in isotope substitutions; for temperatures of 773.15 
$\mathrm{K}$ and higher, the enrichment for all of these isotopologues is comparable to the statistical error.
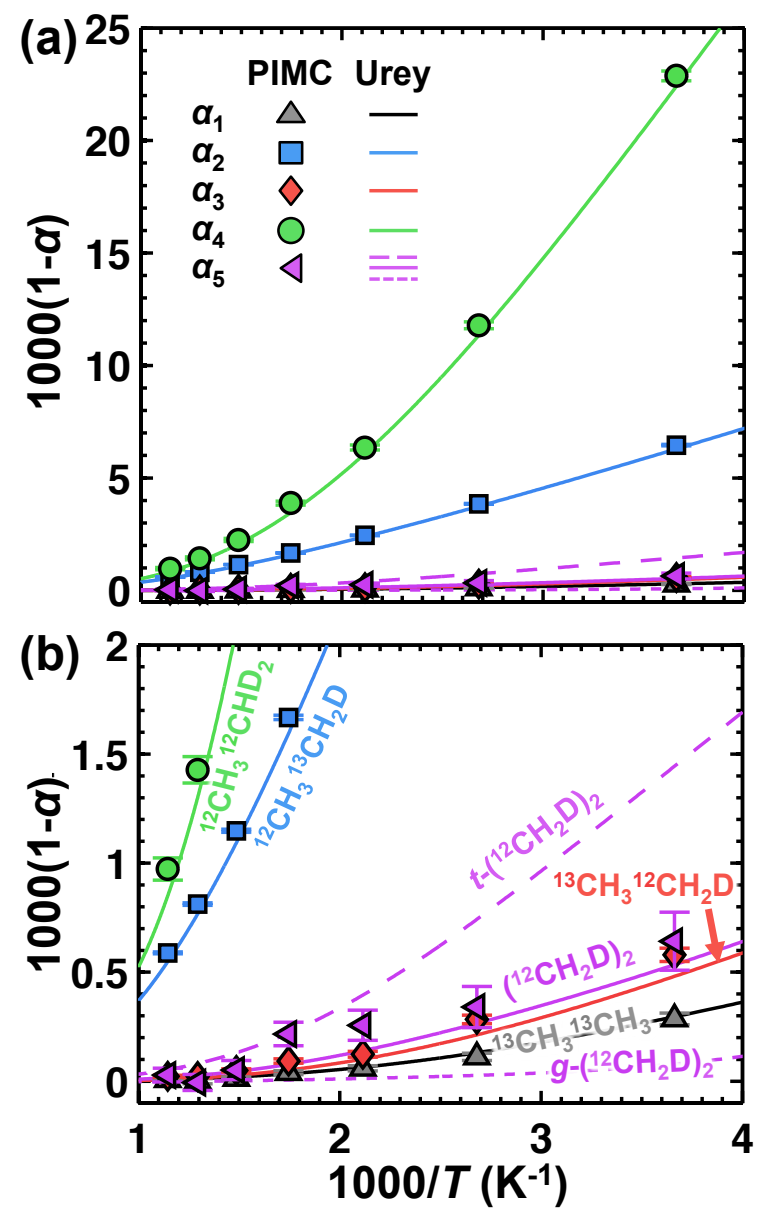

Figure 2: Enrichment of doubly substituted isotopologues of ethane quantified by $1000\left(1-\alpha_{i}\right)$ for Eqs. (10)-(14) as a function of $1000 / T$. Results from PIMC calculations are given by symbols and corresponding Urey-model calculations are given by lines. Panel (b) shows the same data as panel (a) on a different scale. For the Urey-model results for Eq. (14), the solid line indicates results for $t-\left({ }^{12} \mathrm{CH}_{2} \mathrm{D}\right)_{2}$, for which the deuterium isotopes are in a trans conformation, and the dashed line indicates results for $g-\left({ }^{12} \mathrm{CH}_{2} \mathrm{D}\right)_{2}$, for which the deuterium isotopes are in a gauche conformation; the PIMC results include conformational sampling of both rotamers.

\subsection{Comparison with the Urey Model}

To assess whether the Urey model adequately describes isotopologue enrichment for doubly substituted ethane isotopologues, Figure 2 also provides enrichments for the doubly substituted isotopologues in Section 3.1. as predicted by the Urey model using the harmonic frequencies in Table1; selected numerical results are provided in Table 2. The figure shows that the Urey-model results, without any additional corrections, are generally in good agreement with those obtained from PIMC. In particular, the Urey-model results for ${ }^{13} \mathrm{CH}_{3}{ }^{13} \mathrm{CH}_{3}$ are statistically indistinguishable from the PIMC calculations. However, there are statistically resolvable errors in the Urey-model results for the enrichment of both ${ }^{12} \mathrm{CH}_{3}{ }^{13} \mathrm{CH}_{2} \mathrm{D}$ and ${ }^{12} \mathrm{CH}_{3}{ }^{12} \mathrm{CHD}_{2}$. In 
Table 2: Values of $1000\left(1-\alpha_{i}\right)$ to quantify the enrichment of doubly substituted isotopologues in Eqs. (10)-(14). Statistical errors of the mean for PIMC calculations are in parentheses and apply to the last reported number(s) of the estimate.

\begin{tabular}{|c|c|c|c|c|c|c|c|c|c|c|c|}
\hline \multirow{2}{*}{$\mathrm{T}(\mathrm{K})$} & \multicolumn{2}{|c|}{${ }^{13} \mathrm{CH}_{3}{ }^{13} \mathrm{CH}_{3}$} & \multicolumn{2}{|c|}{${ }^{12} \mathrm{CH}_{3}{ }^{13} \mathrm{CH}_{2} \mathrm{D}$} & \multicolumn{2}{|c|}{${ }^{13} \mathrm{CH}_{3}{ }^{12} \mathrm{CH}_{2} \mathrm{D}$} & \multicolumn{2}{|c|}{${ }^{12} \mathrm{CH}_{3}{ }^{12} \mathrm{CHD}_{2}$} & \multicolumn{3}{|c|}{${ }^{12} \mathrm{CH}_{2} \mathrm{D}^{12} \mathrm{CH}_{2} \mathrm{D}$} \\
\hline & PIMC & Urey & PIMC & Urey & PIMC & Urey & PIMC & Urey & PIMC & ${ }^{a}$ Urey & ${ }^{b}$ Urey \\
\hline 273.15 & $0.29(3)$ & 0.295 & $6.46(3)$ & 6.288 & $0.58(3)$ & 0.480 & $22.9(2)$ & 22.382 & $0.64(13)$ & 1.443 & 0.078 \\
\hline 373.15 & $0.11(2)$ & 0.131 & $3.85(2)$ & 3.741 & $0.28(2)$ & 0.212 & $11.8(2)$ & 11.335 & $0.34(9)$ & 0.741 & 0.027 \\
\hline 473.15 & $0.06(1)$ & 0.064 & $2.45(1)$ & 2.391 & $0.12(1)$ & 0.101 & $6.4(1)$ & 6.080 & $0.26(7)$ & 0.394 & 0.013 \\
\hline 573.15 & $0.039(9)$ & 0.034 & $1.67(1)$ & 1.593 & $0.09(1)$ & 0.051 & $3.88(9)$ & 3.453 & $0.21(6)$ & 0.221 & 0.006 \\
\hline 673.15 & $0.013(7)$ & 0.020 & $1.148(8)$ & 1.092 & $0.050(8)$ & 0.027 & $2.24(7)$ & 2.068 & $0.05(4)$ & 0.130 & 0.002 \\
\hline 773.15 & $0.00(1)$ & 0.012 & $0.812(6)$ & 0.766 & $0.022(6)$ & 0.015 & $1.43(6)$ & 1.299 & $-0.01(4)$ & 0.081 & 0.000 \\
\hline 873.15 & $0.008(4)$ & 0.008 & $0.588(4)$ & 0.548 & $0.023(4)$ & 0.008 & $0.97(5)$ & 0.850 & $0.03(3)$ & 0.053 & 0.001 \\
\hline
\end{tabular}

${ }^{a}$ Results for $t-\left({ }^{12} \mathrm{CH}_{2} \mathrm{D}\right)_{2}$

${ }^{b}$ Results for $g-\left({ }^{12} \mathrm{CH}_{2} \mathrm{D}\right)_{2}$

both cases, the Urey-model predictions are systematically lower over the temperature range studied, with the largest error in the isotopologue enrichment being about 0.5 for ${ }^{12} \mathrm{CH}_{3}{ }^{12} \mathrm{CHD}_{2}$ at $273.15 \mathrm{~K}$. Meanwhile, more significant deviations between the Urey-model and PIMC results are found for the enrichment of ${ }^{12} \mathrm{CH}_{2} \mathrm{D}^{12} \mathrm{CH}_{2} \mathrm{D}$. Urey-model predictions of $\alpha_{5}$ provided for both $t-\left({ }^{12} \mathrm{CH}_{2} \mathrm{D}\right)_{2}$ and $g-\left({ }^{12} \mathrm{CH}_{2} \mathrm{D}\right)_{2}(\mathrm{long}$ and short-dashed lines, respectively) both exhibit large deviations from the PIMC results. Simply using a Boltzmann-averaged partition function for ${ }^{12} \mathrm{CH}_{2} \mathrm{D}^{12} \mathrm{CH}_{2} \mathrm{D}$ leads to values that are in much better agreement with the PIMC calculations as shown by the solid, purple line. Piasecki et al. (2016) recently noted the discrepancy between results for $t-\left({ }^{12} \mathrm{CH}_{2} \mathrm{D}\right)_{2}$ and $g-\left({ }^{12} \mathrm{CH}_{2} \mathrm{D}\right)_{2}$, but that study did not employ Boltzmannweighting of these isotopologues, which is necessary to obtain good agreement with the more accurate PIMC calculations.

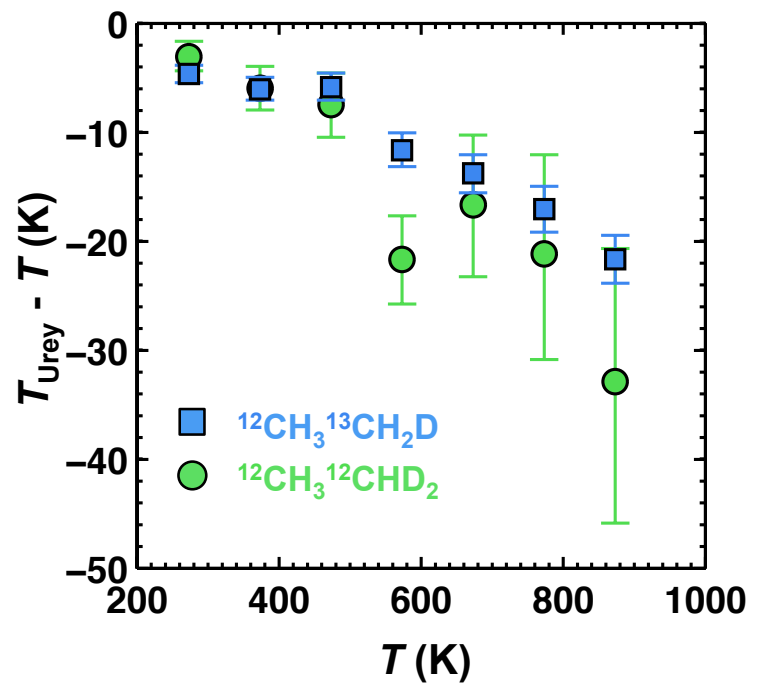

Figure 3: Errors in the apparent equilibrium temperature from Urey-model calculations of the fractionation factors for Eqs. (11) and (13). Taking the PIMC calculations as a reference, temperature errors are computed as the difference in temperature for a given fractionation factor. Error bars reflect the statistical uncertainty of the fractionation factors for Eqs. (11) and (13). 
Figure 3 demonstrates how the errors in Figure 2 affect predictions of apparent equilibrium temperatures. The figure shows the difference in apparent equilibrium temperature obtained from the Urey model compared to PIMC for a given fractionation factor; data for both ${ }^{12} \mathrm{CH}_{3}{ }^{13} \mathrm{CH}_{2} \mathrm{D}$ and ${ }^{12} \mathrm{CH}_{3}{ }^{12} \mathrm{CHD}_{2}$ are shown. The difference $T_{\text {Urey }}-T$ thus represents the approximate error that would result from using theoretical calculations from the Urey model to calibrate experimental measurements. For both isotopologues shown, the relatively minor errors in the fractionation factors lead to correspondingly small deviations at lower temperatures that grow to be as large as $20-30 \mathrm{~K}$ at higher temperatures; at the higher temperatures, the relative temperature errors are less than four percent.

\section{Discussion}

Eqs. (10)-(14) present equilibria for all doubly substituted isotopologues of ethane and feature several relative isotopic mass substitutions at different proximities in the molecule. In the following, we first discuss the enrichment of ${ }^{12} \mathrm{CH}_{3}{ }^{12} \mathrm{CHD}_{2},{ }^{12} \mathrm{CH}_{3}{ }^{13} \mathrm{CH}_{2} \mathrm{D}$, and ${ }^{13} \mathrm{CH}_{3}{ }^{13} \mathrm{CH}_{3}$, which feature isotope substitutions in closest proximity. The discussion is then expanded to consider the enrichment of ${ }^{12} \mathrm{CH}_{2} \mathrm{D}^{12} \mathrm{CH}_{2} \mathrm{D}$ and ${ }^{13} \mathrm{CH}_{3}{ }^{12} \mathrm{CH}_{2} \mathrm{D}$, which feature isotope substitutions on separate methyl groups. More general implications for clumped-isotope effects and for theoretical methods are then discussed.

\subsection{Direct clumped-isotope effects}

For the ethane molecule, the isotopologues ${ }^{12} \mathrm{CH}_{3}{ }^{12} \mathrm{CHD}_{2},{ }^{12} \mathrm{CH}_{3}{ }^{13} \mathrm{CH}_{2} \mathrm{D}$, and ${ }^{13} \mathrm{CH}_{3}{ }^{13} \mathrm{CH}_{3}$ feature double-heavy-isotope substitutions for which the two heavy isotopes appear with the closest possible proximity. The equilibrium enrichments observed in Figure 2 for these isotopologues in addition to possibility to preserve the relevant bonding connectivity upon fragmentation (in the cases of ${ }^{12} \mathrm{CH}_{3}{ }^{12} \mathrm{CHD}_{2}$ and ${ }^{12} \mathrm{CH}_{3}{ }^{13} \mathrm{CH}_{2} \mathrm{D}$ ) make these isotopologues particularly amenable to analysis by mass spectrometry. Figure 2 also sets particular targets for experimental precision. In fact, the slope of the enrichment curves indicates the necessary experimental precision needed to resolve a given temperature difference; in particular, to distinguish a $10 \mathrm{~K}$ temperature difference for samples formed near $373.15 \mathrm{~K}$, paleothermometers based on ${ }^{13} \mathrm{CH}_{3}{ }^{13} \mathrm{CH}_{3},{ }^{12} \mathrm{CH}_{3}{ }^{13} \mathrm{CH}_{2} \mathrm{D}$, or ${ }^{12} \mathrm{CH}_{3}{ }^{12} \mathrm{CHD}_{2}$ will require precisions on the isotopologue enrichment of approximately $0.008,0.02$, or $0.8 \%$, respectively. Even though the required precision for enrichment measurements of ${ }^{12} \mathrm{CH}_{3}{ }^{12} \mathrm{CHD}_{2}$ or ${ }^{12} \mathrm{CH}_{3}{ }^{13} \mathrm{CH}_{2} \mathrm{D}$ will be an order-of-magnitude lower than that required for ${ }^{13} \mathrm{CH}_{3}{ }^{13} \mathrm{CH}_{3}$ to distinguish between similar formation temperatures, this is partially offset by the relative abundances of the isotopes involved.

The results in Figure 2 also show that the fractionation factors due to these clumped-isotope effects order inversely according to the reduced mass of the rare-isotope substitutions, such that the enrichment for ${ }^{12} \mathrm{CH}_{3}{ }^{12} \mathrm{CHD}_{2}>{ }^{12} \mathrm{CH}_{3}{ }^{13} \mathrm{CH}_{2} \mathrm{D}>{ }^{13} \mathrm{CH}_{3}{ }^{13} \mathrm{CH}_{3}$, which is expected based on corresponding reductions in 
vibrational frequency (Urey, 1947, Bigeleisen and Mayer, 1947). However, it is clear that the indirect nature of the D-D coupling in ${ }^{12} \mathrm{CH}_{3}{ }^{12} \mathrm{CHD}_{2}$ results in a weaker effect, as the difference in enrichment between ${ }^{13} \mathrm{C}-\mathrm{D}$ and ${ }^{13} \mathrm{C}-{ }^{13} \mathrm{C}$ clumping (a factor of 23 ) is much larger than that between the indirect $\mathrm{D}-\mathrm{D}$ and ${ }^{13} \mathrm{C}-\mathrm{D}$ clumping (a factor of 3.5). For comparison, the enrichment for doubly deuterated molecular hydrogen $\mathrm{D}_{2}$ at 273.15 K (Urey, 1947, Buchowiecki and Vaníček, 2013), which involves a direct D-D bond, is about 29 times larger than that of ${ }^{12} \mathrm{CH}_{3}{ }^{13} \mathrm{CHD}_{2}$.

\subsection{Indirect clumping effects}

A second-order effect that can also influence fractionation factors is rare-isotope substitution at nonadjacent positions (indirect clumping) in a molecule (Eiler, 2007). Examination of the remaining isotopologues in Figure 2 illustrates the competition between mass perturbation and rare-isotope proximity. The two deuteriums are separated by three bonds in ${ }^{12} \mathrm{CH}_{2} \mathrm{D}^{12} \mathrm{CH}_{2} \mathrm{D}$; the deuterium and ${ }^{13} \mathrm{C}$ are separated by two in ${ }^{13} \mathrm{CH}_{3}{ }^{12} \mathrm{CH}_{2} \mathrm{D}$; and the two ${ }^{13} \mathrm{C}$ are directly bonded in ${ }^{13} \mathrm{CH}_{3}{ }^{13} \mathrm{CH}_{3}$. Despite these differences in separation for the two heavy isotopes, these isotopologues are characterized by similar fractionation factors due to the different isotope masses. It is expected that the clumped-isotope effect will diminish as the two heavy-isotope substitutions occur at more distal locations in the molecule, and these results indicate the strength of the coupling between two heavy-isotope substitutions and how a given pair of heavy-isotope substitutions will affect thermodynamic enrichment in more complex molecules. In particular, enrichment due to deuterium/deuterium substitutions separated by four bonds, deuterium $/{ }^{13} \mathrm{C}$ separated by three bonds, or ${ }^{13} \mathrm{C} /{ }^{13} \mathrm{C}$ by two bonds will be negligible. We note that studies of secondary isotope effects on primary isotope effects have revealed interesting deviations from the rule of the geometric mean (Bigeleisen, 1955), particularly in the context of enzyme-catalyzed reactions where they have been used to interrogate reaction mechanisms (Blanchard and Cleland, 1980, Cook et al., 1981; Amin et al., 1988, Cha et al., 1989, Cook, 1991 , Maharjan et al., 2015); indirect clumping effects might thus record specific patterns in kinetically-controlled processes. Another possibility is to employ measurements of indirect clumping in conjunction with those on direct clumping to confirm equilibration among various substitution sites in a molecule, due to hydrogen isotope exchange with water (Reeves et al., 2012) or other phenomena.

\subsection{Implications for other molecular species and studies}

The results in in Figure 2 also provide insight regarding isotope fractionation in similar molecular species. The enrichments for both ${ }^{12} \mathrm{CH}_{3}{ }^{12} \mathrm{CHD}_{2}$ and ${ }^{12} \mathrm{CH}_{3}{ }^{13} \mathrm{CH}_{2} \mathrm{D}$ bear strong resemblance to their methane analogues, ${ }^{12} \mathrm{CH}_{2} \mathrm{D}_{2}$ and ${ }^{13} \mathrm{CH}_{3} \mathrm{D}$ (see Webb and Miller (2014); Stolper et al. (2014b); Ono et al. (2014); Stolper et al. (2014a, 2015); Liu and Liu (2016); Ma et al. (2008); Wang et al. (2015); Young et al. (2016); Piasecki et al. (2016) for ${ }^{13} \mathrm{CH}_{3} \mathrm{D}$ and see Young et al. (2016); Piasecki et al. (2016) for ${ }^{12} \mathrm{CH}_{2} \mathrm{D}_{2}$ ), but the enrichments for the ethane isotopologues are slightly smaller than the corresponding methane isotopologues. We expect 
this behavior to be somewhat general for comparison of fractionation factors across structurally similar molecular species. For comparison between methane and ethane, one of the methyl groups of ethane might be considered as a large pseudo-atom approximately in the position of one of the hydrogen atoms in methane. The ${ }^{13} \mathrm{C}-\mathrm{D}$ clumping effect in methane with a large pseudo-atom should be smaller than in regular methane because the isotope substitutions are proportionally smaller perturbations. Likewise, we anticipate that the enrichment for ${ }^{12} \mathrm{CH}_{3}{ }^{13} \mathrm{CHD}^{12} \mathrm{CH}_{3}$ (the ${ }^{13} \mathrm{C}$-D clumped-isotope effect at the central position in propane) will be smaller than for ${ }^{12} \mathrm{CH}_{3}{ }^{13} \mathrm{CH}_{2} \mathrm{D}$, which is consistent with recent findings (Piasecki et al., 2016) using the harmonic approximation that the enrichment of ${ }^{13} \mathrm{CH}_{3} \mathrm{D}>{ }^{12} \mathrm{CH}_{3}{ }^{13} \mathrm{CH}_{2} \mathrm{D}>{ }^{12} \mathrm{CH}_{3}{ }^{13} \mathrm{CHD}^{12} \mathrm{CH}_{3}$. This similarity in equilibrium signatures among isotopologues may be interesting when considering natural gas mixtures and discerning the extent that two molecular species record different fractionation histories.

\subsection{Methodological considerations}

The results of Figure 2 and Table 2 have several implications regarding using theoretical methods to predict ethane isotopologue enrichment. First, we find that the Urey model provides a fair description of the enrichment of the equilibria characterizing the doubly substituted isotopologues of ethane; however, it is worth noting that this may be due to a significant cancellation of errors in the partition function ratios, which we have previously observed in other molecular systems (Webb and Miller, 2014). To the extent that the Urey model does exhibit errors relative to PIMC, as for ${ }^{13} \mathrm{CH}_{3}{ }^{12} \mathrm{CH}_{2} \mathrm{D}$ and ${ }^{12} \mathrm{CH}_{2} \mathrm{D}^{12} \mathrm{CH}_{2} \mathrm{D}$, it underestimates the enrichment and manifests as statistically resolvable temperature errors (Figure 3 ). Interestingly, the largest errors in the apparent equilibrium temperature occur at high temperatures, where the errors in fractionation factors are smallest (Figure 2 and Table 2), but the relative errors are still quite small. Based on expectations for molecules like methane, such deviations may be within the uncertainty of experimental measurements (Stolper et al., 2014a, 2015, Wang et al., 2015, Young et al., 2016), but Figure 3 suggests that employing the Urey model for experimental calibration could lead to unnecessary systematic errors.

A recent theoretical study on the enrichment of ${ }^{13} \mathrm{CH}_{3} \mathrm{D}$ illustrated small systematic underestimates of the harmonic approximation after including various corrections (anharmonic correction for zero-point energy, anharmonic correction for vibrational excited states, rotation-vibration coupling correction for zero-point energy, rotation-vibration coupling correction for vibrational excited states, quantum mechanical correction to rotation, and centrifugal distortion correction) to the Urey model (Liu and Liu, 2016). Including perturbative corrections to these ethane isotopologues should result in similar convergence behavior with respect to the PIMC calculations. However, any perturbative corrections to improve the Urey model predictions of the fractionation factors involving ${ }^{12} \mathrm{CH}_{2} \mathrm{D}^{12} \mathrm{CH}_{2} \mathrm{D}$ would have to carefully account for rotameric dependences. Although utilizing a Boltzmann-averaging scheme significantly improved agreement with the PIMC results and is recommended, this approach involves enumerating all stable minima and will become 
more intensive for more complex molecules. Meanwhile, it is appealing that the PIMC calculations do not require exceptional treatments and converge to a common result with sufficient sampling of the proper Boltzmann-weighted ensemble of configurations.

\section{Conclusions}

In this study, we rigorously compute fractionation factors for all doubly substituted isotopologues of ethane using path-integral Monte Carlo and a new potential energy surface developed at the B3LYP/augcc-pVTZ level of theory. The accuracy and precision of the PIMC calculations are practically converged with respect to anticipated experimental precisions, and they can be appropriately used as reference data for calibrating experimental measurements or benchmarking other theoretical approaches. By consideration of all the doubly substituted isotopologues, we quantify the the strength of the clumped-isotope effect, finding that the degree of enrichment decreases in order of deuterium/deuterium, deuterium $/{ }^{13} \mathrm{C}$, and ${ }^{13} \mathrm{C} /{ }^{13} \mathrm{C}$ isotope substitutions if the substitutions have similar spatial separation. However, the decay of the isotopologue enrichment with respect to separation distance suggests that clumping will be negligible at separation distances of greater than three bonds. We additionally find that the Urey model systematically underestimates the enrichment for ${ }^{12} \mathrm{CH}_{3}{ }^{13} \mathrm{CH}_{2} \mathrm{D}$ and ${ }^{12} \mathrm{CH}_{3}{ }^{12} \mathrm{CHD}_{2}$, but results for ${ }^{13} \mathrm{C}-{ }^{13} \mathrm{C}$ clumping are statistically indistinguishable from the PIMC calculations. This underestimation leads to errors in the apparent equilibrium temperature as large as $30 \mathrm{~K}$ at higher formation temperatures, and larger effects may be expected in other systems, given that Urey model can benefit from a substantial cancellation of errors in the computation of isotope fractionation factors (Webb and Miller, 2014). Comparing the two methods also reveals the importance of accounting for rotameric dependences on isotopologue enrichment; whereas the PIMC calculations converge to a single result for ${ }^{12} \mathrm{CH}_{2} \mathrm{D}^{12} \mathrm{CH}_{2} \mathrm{D}$, the Urey model provides distinct results for $t-\left({ }^{12} \mathrm{CH}_{2} \mathrm{D}\right)_{2}$ and $g-\left({ }^{12} \mathrm{CH}_{2} \mathrm{D}\right)_{2}$ rotamers, which must be Boltzmann-averaged to yield reasonable predictions on the relative enrichment of ${ }^{12} \mathrm{CH}_{2} \mathrm{D}^{12} \mathrm{CH}_{2} \mathrm{D}$. Taken together, the results presented here indicate that path-integral methods offer an accurate, robust, and tractable approach for the calculation of clumped-isotope effects in ethane that may be further applied to study clumped-isotope effects in more complex molecules.

\section{Acknowledgements}

This research was supported by the Resnick Sustainability Institute and the Department of Energy (DE-SC0006593). The work of B. J. B. was performed while he was at Emory University and supported by the Office of Basic Energy Sciences and the National Science Foundation. This research used resources of the Oak Ridge Leadership Computing Facility at the Oak Ridge National Laboratory, which is supported by the Office of Science of the U.S. Department of Energy under Contract No. DE-AC05-00OR22725. The authors also thank John Eiler, Alex Sessions, and Brian Peterson for helpful discussions as well as three anonymous reviewers for their helpful and constructive comments. 


\section{References}

Affek, H. P., Eiler, J. M., 2006. Abundance of mass 47 CO2 in urban air, car exhaust, and human breath. Geochim. Cosmochim. Acta 70 (1), 1-12.

Amin, M., Price, R. C., Saunders, W. H., 06 1988. Isotope effects on isotope effects. failure of the rule of the geometric mean as evidence for tunneling. Journal of the American Chemical Society 110 (12), 4085-4086.

Azuri, A., Engel, H., Doron, D., Major, D. T., 2011. Path-Integral Calculations of Nuclear Quantum Effects in Model Systems, Small Molecules, and Enzymes via Gradient-Based Forward Corrector Algorithms. Journal of Chemical Theory and Computation 7 (5), 1273-1286.

Balog, E., Hughes, A. L., Martyna, G. J., 2000. Constant pressure path integral molecular dynamics studies of quantum effects in the liquid state properties of n-alkanes. J. Chem. Phys. 112 (2), 870-880.

Barone, V., 2004. Vibrational zero-point energies and thermodynamic functions beyond the harmonic approximation. J. Chem. Phys. 120 (7), 3059-3065.

Benoit, D. M., 2004. Fast vibrational self-consistent field calculations through a reduced mode-mode coupling scheme. J. Chem. Phys. 120 (2), 562-573.

Bigeleisen, J., 1955. Statistical mechanics of isotopic systems with small quantum corrections. i. general considerations and the rule of the geometric mean. The Journal of Chemical Physics 23 (12), 2264-2267.

Bigeleisen, J., Mayer, M., 1947. Calculation of equilibrium constants for isotopic exchange reactions. J. Chem. Phys. 15 (5), 261-267.

Blanchard, J. S., Cleland, W. W., 07 1980. Kinetic and chemical mechanisms of yeast formate dehydrogenase. Biochemistry 19 (15), 3543-3550

Bohm, M., Schulte, J., Hernandez, E., Ramirez, R., 2001. Electrons and nuclei of ethylene isomers; a Feynman path integral-ab initio study. Chemical Physics 264 (3), 371-400.

Braams, B. J., Bowman, J. M., 2009. Permutationallly invariant potential energy surface in high dimensionality. Int. Rev. Phys. Chem. 28, 577 .

Buchowiecki, M., 2012. Quantum calculations of the temperature dependence of the rate constant and the equilibrium constant for the NH3 + H reversible arrow NH2 + H-2 reaction. Chemical Physics Letters 531, 202-205.

Buchowiecki, M., 2015. Elementary isotope effects - sensitivity to potential energy shape. Chemical Physics Letters 635, 196 200.

Buchowiecki, M., 2016. The ratios of partition functions at different temperatures - sensitivity to potential energy shape ii. Chemical Physics Letters 652, $32-35$.

Buchowiecki, M., Vaníček, J., 2013. Monte carlo evaluation of the equilibrium isotope effects using the takahashi-imada factorization of the feynman path integral. Chemical Physics Letters 588 (0), $11-16$.

Cao, X., Liu, Y., 2012. Theoretical estimation of the equilibrium distribution of clumped isotopes in nature. Geochim. Cosmochim. Acta 77, 292-303.

Ceriotti, M., Markland, T. E., 2013. Efficient methods and practical guidelines for simulating isotope effects. J. Chem. Phys. $138(1)$.

Cha, Y., Murray, C., Klinman, J., 1989. Hydrogen tunneling in enzyme reactions. Science 243 (4896), 1325-1330.

Chandler, D., Wolynes, P. G., 1981. Exploiting the isomorphism between quantum theory and classical statistical mechanics of polyatomic fluids. The Journal of Chemical Physics 74 (7), 4078-4095.

Chen, B., Ivanov, I., Klein, M., Parrinello, M., 2003. Hydrogen bonding in water. Physical Review Letters 91 (21).

Cheng, B., Ceriotti, M., 2014. Direct path integral estimators for isotope fractionation ratios. J. Chem. Phys. 141 (24).

Clayton, C., 1991. Carbon isotope fractionation during natural gas generation from kerogen. Marine and Petroleum Geology $8(2), 232-240$. 
Clog, M., Ling, C., Eiler, J. M., 2012. Measuring doubly ${ }^{13}$ C-substituted ethane by mass spectrometry. AGU Fall Meeting Abstracts.

Clog, M. D., Eiler, J. M., 2014. C-H and C-C clumping in ethane by high-resolution mass spectrometry. AGU Fall Meeting Abstracts.

Clog, M. D., Ferreira, A. A., Santos Neto, E. V., Eiler, J. M., 2014. Ethane C-C clumping in natural gas : a proxy for cracking processes? AGU Fall Meeting Abstracts.

Cook, P., 1991. Enzyme Mechanism from Isotope Effects. Taylor \& Francis.

Cook, P. F., Oppenheimer, N. J., Cleland, W. W., 03 1981. Secondary deuterium and nitrogen-15 isotope effects in enzymecatalyzed reactions. chemical mechanism of liver alcohol dehydrogenase. Biochemistry 20 (7), 1817-1825.

Craig, H., 1953. The geochemistry of the stable carbon isotopes. Geochim. Cosmochim. Acta 3 (2), 53 - 92.

de la Peña, L., Kusalik, P., 2004. Quantum effects in light and heavy liquid water: A rigid-body centroid molecular dynamics study. Journal of Chemical Physics 121 (12), 5992-6002.

Douglas, P. M. J., Stolper, D. A., Smith, D. A., Walter Anthony, K. M., Paull, C. K., Dallimore, S., Wik, M., Crill, P. M., Winterdahl, M., Eiler, J. M., Sessions, A. L., 9 2016. Diverse origins of arctic and subarctic methane point source emissions identified with multiply-substituted isotopologues. Geochimica et Cosmochimica Acta 188, $163-188$.

Eagle, R. A., Schauble, E. A., Tripati, A. K., Tütken, T., Hulbert, R. C., Eiler, J. M., 2010. Body temperatures of modern and extinct vertebrates from 13c-18o bond abundances in bioapatite. Proceedings of the National Academy of Sciences 107 (23), $10377-10382$

Eagle, R. A., Tütken, T., Martin, T. S., Tripati, A. K., Fricke, H. C., Connely, M., Cifelli, R. L., Eiler, J. M., 2011. Dinosaur body temperatures determined from isotopic (13c-18o) ordering in fossil biominerals. Science 333 (6041), 443-445.

Eiler, J. M., 2007. "Clumped-isotope" geochemistry - The study of naturally-occurring, multiply-substituted isotopologues. Earth. Planet. Sci. Lett. 262 (3-4), 309-327.

Eiler, J. M., 2011. Paleoclimate reconstruction using carbonate clumped isotope thermometry. Quaternary Science Reviews $30(25-26), 3575-3588$.

Eiler, J. M., 2013. The Isotopic Anatomies of Molecules and Minerals. Annual Review of Earth and Planetary Sciences 41, 411-441.

Eiler, J. M., Bergquist, B., Bourg, I., Cartigny, P., Farquhar, J., Gagnon, A., Guo, W., Halevy, I., Hofmann, A., Larson, T. E., Levin, N., Schauble, E. A., Stolper, D., 2014. Frontiers of stable isotope geoscience. Chem. Geol. 372,119 - 143.

Eiler, J. M., Clog, M., Magyar, P., Piasecki, A., Sessions, A., Stolper, D., Deerberg, M., Schlueter, H.-J., Schwieters, J., 2013. A high-resolution gas-source isotope ratio mass spectrometer. Int. J. Mass spectrom. 335 (0), 45 - 56.

Eiler, J. M., Schauble, E., 2004. (OCO)-O-18-C-13-O-16 in Earth's atmosphere. Geochim. Cosmochim. Acta 68 (23), $4767-4777$. Feynman, R. P., Hibbs, A. R., 1965. Quantum Mechanics and Path Integrals. McGraw-Hill Companies.

Finnegan, S., Bergmann, K., Eiler, J. M., Jones, D. S., Fike, D. A., Eisenman, I., Hughes, N. C., Tripati, A. K., Fischer, W. W., 2011. The Magnitude and Duration of Late Ordovician-Early Silurian Glaciation. Science 331 (6019), $903-906$.

Freeman, KH and Hayes, JM and Trendel, JM and Albrecht, P, 1990. Evidence From Carbon Isotope Measurements For Diverse Origins Of Sedimentary Hydrocarbons. Nature 343 (6255), 254-256.

Ghosh, P., Adkins, J., Affek, H., Balta, B., Guo, W., Schauble, E., Schrag, D., Eller, J., 2006. (13)C-(18)O bonds in carbonate minerals: A new kind of paleothermometer. Geochimica et Cosmochimica Acta 70 (6), 1439-1456.

Ghosh, P., Garzione, C. N., Eiler, J. M., 2006. Rapid uplift of the altiplano revealed through 13c-18o bonds in paleosol carbonates. Science 311 (5760), 511-515.

Grauel, A.-L., Schmid, T. W., Hu, B., Bergami, C., Capotondi, L., Zhou, L., Bernasconi, S. M., 2013. Calibration and application of the 'clumped isotope' thermometer to foraminifera for high-resolution climate reconstructions. Geochim. Cosmochim. Acta 108, 125-140. 
Habershon, S., Manolopoulos, D. E., 2011. Thermodynamic integration from classical to quantum mechanics. J. Chem. Phys. $135(22), 224111$.

Halpern, A. M., Glendening, E. D., 2003. An intrinsic reaction coordinate calculation of the torsional potential in ethane: Comparison of the computationally and experimentally derived torsional transitions and the rotational barrier. J. Chem. Phys. 119 (21), 11186-11191.

Hayes, J., Freeman, K. H., Popp, B. N., Hoham, C. H., 1990. Proceedings of the 14th international meeting on org geochem. compound-specific isotopic analyses: A novel tool for reconstruction of ancient biogeochemical processes. Org Geochem. $16(4), 1115-1128$.

Herrero, C., Ramirez, R., 2011. Isotope effects in ice Ih: A path-integral simulation. J. Chem. Phys. 134 (9).

Hidalgo-Olguín, D. R., Villa, M., Senent, M. L., Mora-Delgado, M. A., 2008. Ethane internal rotation-vibrational hamiltonian. J. Mex. Chem. Soc. 52 (1), 98-102.

Hill, P. S., Tripati, A. K., Schauble, E. A., 2014. Theoretical constraints on the effects of ph, salinity, and temperature on clumped isotope signatures of dissolved inorganic carbon species and precipitating carbonate minerals. Geochim. Cosmochim. Acta $125,610-652$.

Huntington, K. W., Budd, D. A., Wernicke, B. P., Eiler, J. M., 2011. Use Of Clumped-isotope Thermometry To Constrain The Crystallization Temperature Of Diagenetic Calcite use Of Clumped-isotope Thermometry To Constrain The Crystallization Temperature Of Diagenetic Calcite. Journal Of Sedimentary Research 81 (9-10), 656-669.

Liu, J., Andino, R. S., Miller, C. M., Chen, X., Wilkins, D. M., Ceriotti, M., Manolopoulos, D. E., 2013. A Surface-Specific Isotope Effect in Mixtures of Light and Heavy Water. Journal of Physical Chemistry C 117 (6), $2944-2951$.

Liu, Q., Liu, Y., 2016. Clumped-isotope signatures at equilibrium of ch4, nh3, h2o, h2s and so2. Geochim. Cosmochim. Acta $175,252-270$.

Liu, Q., Tossell, J. A., Liu, Y., 2010. On the proper use of the Bigeleisen-Mayer equation and corrections to it in the calculation of isotopic fractionation equilibrium constants. Geochim. Cosmochim. Acta 74 (24), 6965-6983.

Lynch, V. A., Mielke, S. L., Truhlar, D. G., 2004. Accurate vibrational-rotational partition functions and standard-state free energy values for H2O2 from Monte Carlo path-integral calculations. J. Chem. Phys. 121 (11), 5148-5162.

Lynch, V. A., Mielke, S. L., Truhlar, D. G., 2005. High-precision quantum thermochemistry on nonquasiharmonic potentials: Converged path-integral free energies and a systematically convergent family of generalized Pitzer-Gwinn approximations. Journal of Physical Chemistry A 109 (44), 10092-10099.

Ma, Q., Wu, S., Tang, Y., 2008. Formation and abundance of doubly-substituted methane isotopologues ((CH3D)-C-13) in natural gas systems. Geochim. Cosmochim. Acta 72 (22), 5446-5456.

Magyar, P. M., Orphan, V. J., Eiler, J. M., 2016. Measurement of rare isotopologues of nitrous oxide by high-resolution multi-collector mass spectrometry. Rapid Communications in Mass Spectrometry 30 (17), 1923-1940, rCM-16-0086.R1.

Maharjan, B., Raghibi Boroujeni, M., Lefton, J., White, O. R., Razzaghi, M., Hammann, B. A., Derakhshani-Molayousefi, M., Eilers, J. E., Lu, Y., 05 2015. Steric effects on the primary isotope dependence of secondary kinetic isotope effects in hydride transfer reactions in solution: Caused by the isotopically different tunneling ready state conformations? Journal of the American Chemical Society 137 (20), 6653-6661.

Markland, T. E., Berne, B. J., 2012. Unraveling quantum mechanical effects in water using isotopic fractionation. Proceedings of the National Academy of Sciences of the United States of America 109 (21), 7988-7991.

Marsalek, O., Chen, P.-Y., Dupuis, R., Benoit, M., Méheut, M., Bačić, Z., Tuckerman, M. E., 2014. Efficient calculation of free energy differences associated with isotopic substitution using path-integral molecular dynamics. Journal of Chemical Theory and Computation 10 (4), 1440-1453.

McQuarrie, D. A., 2000. Statistical Mechanics. Univ Science Books.

Mielke, S. L., Dinpajooh, M., Siepmann, J. I., Truhlar, D. G., 2013. Efficient methods for including quantum effects in monte 
carlo calculations of large systems: Extension of the displaced points path integral method and other effective potential methods to calculate properties and distributions. J. Chem. Phys. 138 (1), 014110.

Mielke, S. L., Truhlar, D. G., 2009. Improved Methods for Feymnan Path Integral Calculations of Vibrational-Rotational Free Energies and Application to Isotopic Fractionation of Hydrated Chloride Ions. Journal of Physical Chemistry A 113 (16), $4817-4827$

Mielke, S. L., Truhlar, D. G., 2012. Accelerating the Convergence and Reducing the Variance of Path Integral Calculations of Quantum Mechanical Free Energies by Using Local Reference Potentials. Journal of Chemical Theory and Computation $8(5), 1589-1596$.

Ono, S., Wang, D. T., Gruen, D. S., Lollar, B. S., Zahniser, M. S., McManus, B. J., Nelson, D. D., 2014. Measurement of a doubly substituted methane isotopologue, 13ch3d, by tunable infrared laser direct absorption spectroscopy. Anal. Chem. 86 (13), 6487-6494.

Paesani, F., Iuchi, S., Voth, G. A., 2007. Quantum effects in liquid water from an ab initio-based polarizable force field. J. Chem. Phys. 127 (7).

Pérez, A., von Lilienfeld, O. A., 2011. Path integral computation of quantum free energy differences due to alchemical transformations involving mass and potential. Journal of Chemical Theory and Computation 7 (8), 2358-2369.

Piasecki, A., Sessions, A., Peterson, B., Eiler, J., 10 2016. Prediction of equilibrium distributions of isotopologues for methane, ethane and propane using density functional theory. Geochimica et Cosmochimica Acta 190, 1-12.

Pinilla, C., Blanchard, M., Balan, E., Ferlat, G., Vuilleumier, R., Mauri, F., 2014. Equilibrium fractionation of H and O isotopes in water from path integral molecular dynamics. Geochimica et Cosmochimica Acta 135, 203-216.

Redlich, O., 1935. A general relationship between the oscillation frequency of isotropic molecules - (with remarks on the calculation of harmonious force constants). Zeitschrift Fur Physikalische Chemie-Abteilung B-Chemie Der Element Arprozesse Aufbau Der Materie 28 (5), 371-382.

Reeves, E. P., Seewald, J. S., Sylva, S. P., 1 2012. Hydrogen isotope exchange between n-alkanes and water under hydrothermal conditions. Geochimica et Cosmochimica Acta 77, 582-599.

Richet, P., Bottinga, Y., Jayvoy, M., 1977. Review of hydrogen, carbon, nitrogen, oxygen, sulfur, and chlorine stable isotope fractionation among gaseous molecules. Annual Review of Earth and Planetary Sciences 5, 65-110.

Rustad, J. R., Bylaska, E. J., Jackson, V. E., Dixon, D. A., 5 2010. Calculation of boron-isotope fractionation between b(oh)3(aq) and. Geochimica et Cosmochimica Acta 74 (10), 2843-2850.

Rustad, J. R., Nelmes, S. L., Jackson, V. E., Dixon, D. A., 01 2008. Quantum-chemical calculations of carbon-isotope fractionation in $\operatorname{co} 2(\mathrm{~g})$, aqueous carbonate species, and carbonate minerals. The Journal of Physical Chemistry A 112 (3), $542-555$.

Schoell, M., 1984. Recent advances in petroleum isotope geochemistry. Org Geochem. 6 (0), $645-663$.

Schweizer, K. S., Stratt, R. M., Chandler, D., Wolynes, P. G., 1981. Convenient and accurate discretized path integral methods for equilibrium quantum mechanical calculations. J. Chem. Phys. 75 (3), 1347-1364.

Sessions, A. L., Burgoyne, T. W., Schimmelmann, A., Hayes, J. M., 1999. Fractionation of hydrogen isotopes in lipid biosynthesis. Org Geochem. 30 (9), $1193-1200$.

Stolper, D., Martini, A., Clog, M., Douglas, P., Shusta, S., Valentine, D., Sessions, A., Eiler, J., 2015. Distinguishing and understanding thermogenic and biogenic sources of methane using multiply substituted isotopologues. Geochim. Cosmochim. Acta $161,219-247$.

Stolper, D., Sessions, A., Ferreira, A., Neto, E. S., Schimmelmann, A., Shusta, S., Valentine, D., Eiler, J., 2014a. Combined 13c- $\mathrm{d}$ and $\mathrm{d}-\mathrm{d}$ clumping in methane: Methods and preliminary results. Geochim. Cosmochim. Acta $126,169-191$.

Stolper, D. A., Lawson, M., Davis, C. L., Ferreira, A. A., Neto, E. V. S., Ellis, G. S., Lewan, M. D., Martini, A. M., Tang, Y., Schoell, M., Sessions, A. L., Eiler, J. M., 2014b. Formation temperatures of thermogenic and biogenic methane. Science 
344 (6191), 1500-1503.

Sturup, S., Hansen, H. R., Gammelgaard, B., 2008. Application of enriched stable isotopes as tracers in biological systems: a critical review. Analytical and Bioanalytical Chemistry 390 (2), 541-554.

Tuckerman, M. E., 2010. Statistical Mechanics: Theory and Molecular Simulation (Oxford Graduate Texts). Oxford University Press, USA.

Urey, H., 1947. The thermodynamic properties of isotopic substances. J. Chem. Soc., 562-581.

Wang, D. T., Gruen, D. S., Lollar, B. S., Hinrichs, K.-U., Stewart, L. C., Holden, J. F., Hristov, A. N., Pohlman, J. W., Morrill, P. L., Könneke, M., Delwiche, K. B., Reeves, E. P., Sutcliffe, C. N., Ritter, D. J., Seewald, J. S., McIntosh, J. C., Hemond, H. F., Kubo, M. D., Cardace, D., Hoehler, T. M., Ono, S., 2015. Nonequilibrium clumped isotope signals in microbial methane. Science 348 (6233), 428-431.

Wang, D. T., Welander, P. V., Ono, S., 11 2016. Fractionation of the methane isotopologues 13ch4, 12ch3d, and 13ch3d during aerobic oxidation of methane by methylococcus capsulatus (bath). Geochimica et Cosmochimica Acta 192, 186-202.

Wang, Y., Sessions, A. L., Nielsen, R. J., Goddard, III, W. A., 2009. Equilibrium H-2/H-1 fractionations in organic molecules: I. Experimental calibration of ab initio calculations. Geochim. Cosmochim. Acta 73 (23), 7060-7075.

Wang, Z. G., Schauble, E. A., Eiler, J. M., 2004. Equilibrium thermodynamics of multiply substituted isotopologues of molecular gases. Geochim. Cosmochim. Acta 68 (23), 4779-4797.

Webb, M. A., Miller, III, T. F., 2014. Position-specific and clumped stable isotope studies: Comparison of the urey and pathintegral approaches for carbon dioxide, nitrous oxide, methane, and propane. Journal of Physical Chemistry A 118 (2), $467-474$.

Whiticar, M. J., 1990. A geochemical perspective of natural-gas and atmospheric methane. Org Geochem. 16 (1-3), 531-547.

Wolfsberg, M., Hook, W. A., Paneth, P., Rebelo, L. P. N., 2009. Isotope Effects in the Chemical, Geological and Bio Sciences. Springer Netherlands.

Yeung, L. Y., Ash, J. L., Young, E. D., 2015. Biological signatures in clumped isotopes of o2. Science 348 (6233), $431-434$.

Yeung, L. Y., Young, E. D., Schauble, E. A., 2012. Measurements of 18o18o and 17o18o in the atmosphere and the role of isotope-exchange reactions. Journal of Geophysical Research: Atmospheres 117 (D18), n/a-n/a.

Young, E. D., III, D. R., Freedman, P., Mills, M., 2016. A large-radius high-mass-resolution multiple-collector isotope ratio mass spectrometer for analysis of rare isotopologues of o2, n2, $\{\mathrm{CH} 4\}$ and other gases. International Journal of Mass Spectrometry $401,1-10$.

Zimmermann, T., Vaníček, J., 2009. Path integral evaluation of equilibrium isotope effects. J. Chem. Phys. 131 (2). 